\title{
Ethnicity, Homogeneity, Nation
}

\section{A Relationship of Tension}

Samuel Salzborn

\begin{abstract}
The categories of ethnicity, homogeneity and the nation partially contradict each other, but they also overlap. In order to examine this tension, this article will consider these terms in the context of the question that mediates their relationship, namely, the stability and instability of political orders. My aim is to articulate a conceptual framework that makes it possible to discuss this relationship of tension and sketch it from a theoretical perspective.
\end{abstract}

Keywords: democracy, ethnicity, homogeneity, nation, political order, political theory

The categories of ethnicity, homogeneity and the nation partially contradict each other, but they also overlap. In order to examine this tension, this article will consider these terms in the context of the question that mediates their relationship, namely, the stability and instability of political orders. My aim is to articulate a conceptual framework that makes it possible to discuss this relationship of tension and sketch it from a theoretical perspective.

There has been much discussion on this topic, producing, amongst other things, a series of case studies in international contexts. Yet little work has been done to reflect conceptually and systematically on the formation and disintegration of political orders (cf. Fukuyama 2011,2014$)$. This may have to do with the fact that the circumstances of individual cases are, of course, specific. However, it may also have to do with the fact that the perspective of comparative 
research on democracy and autocracy strongly focusses on framing its questions in terms of political systems as concrete forms of organisation. This research tends less towards considering these systems abstractly as (competing) political orders. In this regard, considering individual cases makes it difficult to identify general tendencies on a global political scale both historically and in the present moment.

In order to grasp the relevance that notions of ethnicity and nationhood have for the stability or instability of political orders, it is necessary to look at the central category of modern political thought: the state. The formation and disintegration of states are phenomena indicating that the modern state itself should not be understood as something stable and unchanging but as a process. In the language of Georg Jellinek (1900): the state is never a substance, but always only a function. And this understanding is central, in equal measure, for the emergence and dissolution of states, since as a state this institutionalised form takes shape, transforms or ceases to exist only, and always, when this process is actively carried out by human beings. In this regard, the state is in no way sacrosanct; it always derives its legitimacy from the fact that a sufficient mass of people trust this legitimacy and thus the state itself.

The formation and disintegration of political orders can in principle thus also be described in terms of erosions in the systems of legitimation. Here, trust in the respective concrete state is linked with the hope that the concrete state will be functional as the embodiment of the abstract state. Or to put it precisely the other way around: in these erosions, this hope is denied, with reference to competing ideas of political order such as the empire, the ekklesia, the Tiānxià, the umma, pan-ideologies, tribalism or anarchy (cf. Salzborn 2017). The key to understanding the formation and disintegration of political orders is thus the question of legitimacy.

\section{The State and Legitimacy}

During the transition from the pre-modern state of the Middle Ages, which was based on personal allegiances, to the institutional state of modern times, a political understanding of a new system of rule developed. This system was based on a clearly defined territory 
with a monopolised central power and a state population administered with expectations of continuity and permanence. At the threshold between the pre-modern and modern periods, numerous strands of development cumulated in a process in which the modern nation state took shape, in the sense defined by Jellinek (1900), as an entity characterised in constitutional terms by a unity of its territory, sovereignty and population. This legally established threedimensionality of the concept of the state (which is often called the 'doctrine of three elements') gives rise to the range of variations in the question of legitimacy. If a state's territoriality, sovereignty and population are its constitutive criteria, they also represent modes that can serve not only to legitimise it but also to delegitimise it. These criteria are therefore fundamentally ambivalent and constitutive for the abstract state only as functional categories. As substantial categories, by contrast, they can also invalidate concrete states.

Thus, to take one example, it is accepted in research into theories of the state that a clearly demarcated and well-defined state territory is a characteristic of the (abstract) state. Nevertheless, the ethno-nationalist claims of regionalist and separatist movements constantly demonstrate that the territory of concrete states is disputed. Hence, all three constitutive elements of the state - territory, sovereignty and population - are also potential areas of conflict that can lead to the disintegration of a concrete political order and the formation of one (or more) new orders.

State sovereignty is structurally characterised by the establishment and maintenance of a monopoly on the use of violence. To follow Max Weber (1921) and Ernest Renan (2018), the legitimacy of this monopoly rests upon an act of continuous acceptance; the state's claim to a monopoly on the legal use of physical force, both internally and externally, nevertheless manifests itself in its claim to unity. At the same time, this claim to unity also decisively shapes and supports a state's sovereignty, at least in the material sense. A state's territory situates the sphere of rule and thus influence of the respective state system, thereby limiting the scope of state sovereignty while unifying it in its double orientation - inwards as the sovereignty of the people and outwards as the sovereignty of a single state actor. This, in turn, necessarily and inevitably generates, in the words of Niklas Luhmann (1998), a structure of inclusion and exclusion. However, this inclusion and exclusion is concretely 
determined according to fundamentally differing criteria. A state's border, which clearly separates its territory from other states on land, at sea, and in the air, territorially limits the influence of all state institutions. And at the same time, from the perspective of its inner space, it presumes to territorially guarantee these institutions.

The most controversial of these three points is a state's population. The minimal legal approach that Immanuel Kant follows defines a state as a 'union of a multitude of human beings under laws of right' (1797: 456-457). Kant's concern is with the a priori justification of these laws and the normative force of this 'idea' as being in accordance with 'pure principles of right' for 'every actual union into a commonwealth'. But he leaves out any concrete discussion of the key question relevant to the issue at hand, namely: who becomes or can become a citizen of a state, and according to which criteria? In the social sciences, two models are typically employed here to answer this question: one that is republican and one that is based on the notion of a nation. That is, scholars either use a model of affiliation based on a (rational) political declaration or a model based on (irrational) factors such as birth or descent. Both procedures generate a particular efficacy for conceptions of inclusion and exclusion. The only formal-rational regulation of the question of who belongs to a state's population is the empirically verifiable affiliation to a nation state by means of formalised regulations governing nationality. However, the promulgation of such regulations always remains controversial in structural terms because the political pre-conditions that allow nationality to be legally justified remain controversial (cf. Gosewinkel 2016).

Processes of state disintegration can begin with any of these three elements. They can accordingly begin by questioning a state's sovereignty, territory or population, claiming that the respectively valid agreements in any concrete state do not correspond to the subjectively intended ideal of the abstract state. Such a critique gives rise to a demand for change: both non-violent (which, as a rule, would not be called 'disintegration' but 'transformation') and violent (through internal and/or external forces, including separatism and civil war as well as intervention and occupation). This also shows that the process of state disintegration is moderated not only by the axis of differentiation of internal-external, but also of abovebelow. The impulse that initiates instabilities of the (homogeneous) 
system of norms, up to state disintegration, can lie on both levels: that of the degeneration of the structure of rule and thus of the political system, as well as that of political culture, that is, of society.

\section{Material and Substantial Sovereignty}

Although processes of state disintegration can be applied to all dimensions of state differentiation, they nevertheless manifest a specificity that corresponds to the question of sovereignty. Sovereignty in a material sense, that is, as realised executive power to rule, is the necessary pre-requisite for establishing and stabilising the monopoly on the use of violence. However, it would be too quick to narrow the conceptualisations of sovereignty, both in the history of ideas and in actual history, to this one moment as most prominently articulated by Carl Schmitt (1922) in reference to the state of emergency. Sovereignty can and must be conceptualised not only from an executive perspective, but always also from a legislative one. Sovereignty in the executive sense only exists if the (executive) sovereign is able to decide on the state of emergency. Nevertheless, and even more so, the executive and thus material sovereign only acquires this power at all because this power is granted by the legislative and thus material sovereign in a relationship of legitimate representation. This is crucial because the concept of sovereignty describes a reciprocal relationship that Thomas Hobbes and Niccolò Machiavelli had already emphasised as central: the power to be allowed to decide on the state of emergency (not: to be able to decide - that is another question) is something the material sovereign attains exclusively by virtue of the fact that that this power is entrusted to the material sovereign by the substantial sovereign, that is, the citizens (cf. Salzborn 2015). What is at stake here, as Jellinek (1900) has argued, is thus a sovereign state that is the expression, result and starting point for conflicts of interest that are based on social, that is, reversible human relations. Material sovereignty must be seen as the foundation (though not as a guarantee) for any democratic development that is expected to be sustainable and produce political stability. To state the point in terms of Ernst-Wolfgang Böckenförde's (1976) paradoxical-yet-correct phrase: the material sovereignty of the executive must guarantee 
normative homogeneity, which is something it can never guarantee on account of substantial sovereignty.

The actual historical core of sovereignty is economic - it consists in securing property relations and enabling relationships of exchange. Moreover, the fundamental core of sovereign relationships is also a relationship of exchange: the material sovereign was empowered to act by the substantial sovereign and assumed, in return, a guarantee for the latter: to safeguard individual freedoms. If a sovereign forfeits this mandate, its legitimate authorisation to exercise the monopoly on violence also lapses. This is crucially important because one ultimately finds, in the concepts of material and substantial sovereignty or external (state) sovereignty and internal (popular) sovereignty, the lever for the development of a number of processes of state disintegration. This is because abolishing the legitimising foundation of sovereignty is tantamount to calling into question its monopoly on the use of violence, regardless of whether this is carried out gradually or radically.

Moreover, considering the option of a state of emergency, the question of the monopoly on the use of violence ultimately determines the question of stability or instability of states. Unlike authoritarian or totalitarian systems, democratic systems are characterised by conflicts of interest and power struggles that do not contest sovereignty but rather enable its legitimacy in the first place. As Hermann Heller writes: 'Social homogeneity can ... never mean the suspension of the necessary antagonistic social structure' (1928: 428). Based on the freedom and equality of people, this legitimate sovereignty consists in recognising the sphere of private life, in which individuals live freely and in self-determination as individual citizens, that is, with the ability to exercise, without state influence and interference, their basic rights and freedoms up to the point where these rights and freedoms would violate those of other individuals. It is essential that the sovereign state become the space enabling social and political conflicts with fault lines that are not homogeneous but heterogeneous, meaning that they are constantly changing and may even overlap in some cases. It is in this sense that the permanent tension between a homogeneous normative order and social heterogeneity is the truth of the modern nation state.

In this relationship of tension between external form as a state in itself and the lack or absence of internal conditions as a state for 
itself is thus the essential legitimising moment for the disintegration and subsequent formation processes of political orders. In the UN system of international law, for instance, all concrete states are accorded the quality of being states in itself. However, the majority of these states do not meet the requirements for being a state for itself. For although these states evince a political system, in autocratic or totalitarian systems the state's monopoly on the use of violence is based not on sovereignty but on repressive violence. Especially in autocratic systems, the legitimising function of sovereignty, that is, the safeguarding and granting of individual freedoms, is questionable.

To put it another way, these systems are undemocratic not only because their constitutional norms are internally homogeneous but also because there is an expectation that their constitutional reality be homogeneous - through a forced suspension of social heterogeneity. A homogeneous system of norms and a heterogeneous reality constitute, abstractly speaking, the basic structure of democracy. $A$ homogeneous system of norms and a homogeneous reality constitute the basic structure of autocracy. A heterogeneous system of norms and a homogeneous reality constitute the basic structure of totalitarian systems. And a heterogeneous system of norms and a heterogeneous reality constitute that the basic structure of anarchy.

\section{Political Culture and Political Orders}

We can classify empirical processes of state disintegration in terms of this model. The model distinguishes between internal and external factors, as well as between a state's political system and political culture, as the sites where conflicts can be located. And it differentiates, on the horizontal level, between a state's sovereignty, territory and population. But it still lacks an analytical instrument that would allow us to explain û not only descriptively but also theoretically, in terms of a theory about the state - how processes of (national) state disintegration occur. We lack a tool that would allow us to understand these processes. A potential for stabilisation and simultaneous destabilisation of the political order is inherent within the relationships of power or rule institutionalised within any state system. This potential mediates the relationship, in a state's political culture, 
between this order's legality and legitimacy, and for this reason the key to the question of stability is that of legitimacy. It may be the case that, in the horizontal axes of a state's processes of coming to a common understanding regarding its sovereignty, territory and population, an agreement regarding the needs of a state's subjects is achieved that they interpret as sufficient. In this case, there are no tensions in the vertical axis between the political system and the political culture. However, the greater the perception of difference is in one or more of the fields on the horizontal axis, the greater the tensions will be on the vertical axis. A conceptual instrument from the field of cultural research on politics can help clarify how constellations of conflict might arise and develop: to wit, the model of one or more 'unwritten constitutions' or 'unwritten rules' (Birs1 and Salzborn 2014).

In the context of the history of ideas in German scholarship, the concept of an unwritten constitution refers to discussions on constitutional law from the period of the Weimar Republic. These discussions conceptually differentiated between constitutional norm and constitutional reality (Verfassungswirklichkeit and Verfassungsrealität), and this issue is still common in German jurisprudence today. In his Constitutional Theory, Schmitt (1928) had criticised the approaches of normativism and positivism with their respective focuses on the closed system of norms and the positive constitutional order, pointing to a processual dynamic in the political sphere that, he argued, could never be made comprehensible by a purely positive understanding of law. In addition to the positivist shaping of political orders through the assertion of norms, the individual and collective processes of processing and reflection within the societies Schmitt studied also played a central role especially that of political will. This entails the conclusion that the existence and knowledge of norms is not synonymous with their acceptance. Legal-sociological discussions in the wake of Schmitt have adopted this differentiation between norms and reality. But they have questioned his decisionist articulation and voluntaristic re-accentuation of social reality, which for him took the shape of an ethnically homogeneous ideal of community. This ideal led Schmitt to postulate the primacy of extra-legal categories (will, a people, the common good, morals, etc.) for law-making (cf. Fraenkel 1941; and Neumann 1944). In its relevance for theories of the state and 
of law, this debate therefore emphasises conflicts between constitutional norms and constitutional reality and thus between written and unwritten constitution(s) or rules that hold the keys to analysing the beginning, intensity and progress of processes of state disintegration.

As variants on the vertical axis, three fields of possibility arise for determining the relationship between unwritten rules and established norms:

1. The unwritten rules of the political within a society are (largely) identical to, or at least do not conflict with, its formal rules and institutions (cf. Göhler 1997; and Lauth and Liebert 1999). In this respect, constitutional reality supports the constitutional norm and the unwritten rules lead to a stable constitutional order.

2. The unwritten constitution(s) contradict the written constitution and thus engender tension between the constitutional norm and the constitutional reality. These unwritten rules have the effect of pushing for changes in existing norms, which can be either constructive or destructive in the sense of (an increase of) democratisation and (an increase of) autocratisation.

3. The unwritten rules of the political give rise to political apathy and thus also lead to stability, since their actors do not become socially or politically active in any way. In liberal democracies, there has been talk for some time of disenchantment with politics or parties; this is in fact a diagnosis of a situation in which the actors concerned do not want to participate and are therefore apathetic in the traditional sense articulated by Gabriel Almond and Sydney Verba (1963).

If one summarises these forms of modelling, then the following conceptual framework emerges for processes by which political orders disintegrate - and at the same time also vice versa for those by which political orders emerge: the horizon towards which each concrete state aims consists in a procedural approach to an idealtypical (and thus never attainable) freedom from conflict between the elements of the abstract state (i.e. between a state's sovereignty, territory and population). The questioning of these three elements, 
whether in isolation or even as overlapping, derives from the fact that none of them can be defined in a legally conclusive manner insofar as their object is itself social in nature and must therefore remain a matter of conflict and disagreement.

And this is precisely wherein the dialectic of the formation and disintegration of political orders lies: every concrete state exists in the knowledge that it is finite, since it was itself the product of the disintegration or destruction of a previous, different political order - a nuance towards which Hobbes' (1651) prominent metaphor of the 'mortal god' already nods.

Every concrete state tries to achieve the highest possible degree of congruence between the norms it proclaims and the acceptance of these norms within its territory. However, these norms always remain at least in conflict with the claim of the abstract state and, above all, in reality, with competing conceptions for alternative forms of the concrete state as another state. Only the sovereign dimension of state rule can be objectively measured (i.e. the question of the relationship between internal and external sovereignty, or between substantive and material sovereignty). In addition to horizontal differentiation, vertical differentiation also plays a role here. This vertical differentiation reflects, in particular, the relationship between internal and external causes of state disintegration processes. For this reason, depending on the concrete constellation, the responsibility for initiating processes of disintegration lies not only in the political culture - and thus the subjective dimension of the political - but also in the structural factors at play.

\section{Social Belief in Ethnicity and Political Instability}

This is also the point at which the gradual question of the necessity of having normative homogeneity in relation to social heterogeneity becomes relevant for the continued existence of the concrete (national) state: conflicts within societies and between social subgroups can be integrated only under one condition: if the degree of internal (popular) sovereignty is at least considered sufficient from the subjective perspective of those affected. In all other cases, the political-social claims that are formulated in ethno-cultural terms generate partial or general processes of disintegration of the 
concrete political order - and this always occurs when a "belief in common ethnicity" (Weber 1921: 389) is formulated in a certain way: as a pre-political belief with a claim to produce collective and socially homogeneity, which counteracts pluralistic heterogeneity and calls into question the social basis of the normative order.

Not all nationalisms are equal, after all. Combined with a collectively homogenising belief in ethnicity, nationalism becomes a basis to undo the normative order of democracy. In the terms used by Norbert Elias, nationalism can be described as 'one of the most powerful, if not the most powerful, social belief systems of the nineteenth and twentieth centuries'. It represents a world view constructed in particular along the ascribed collective identity of language, culture, religion and history, which facilitates the social creation, political mobilisation and psychological integration of larger associations of solidarity - such as, in recent times, the nation. The nation initially functions merely as an 'imagined community' (Anderson 1983) and 'order conceived in thought' (Wehler 2001: 13), which develops through the inclusion of the traditions of an association of rulers and is transformed by nationalism, gradually and continually, into a unit of action. As a phenomenon of the modern period, nationalism is linked to a politicisation of the concepts of a people (Volk) and nation, whose previously separately retrievable uses in terms of specific strata and groups were standardised and, at the same time, made ideological - always in connection with an ostensible openness directed towards the future (cf. Koselleck 1992).

In this respect, nationalism as an ideology of integration creates an awareness of belonging together linked with the awareness of having a common past, common opponents and common goals for the future. The nation thereby makes a moral, political, social and historical claim as an 'ultimate value' (Dieter Langewiesche) or 'ultimate instance' (Reinhart Koselleck) and thus as the highest source of legitimacy, which cannot be undone or exceeded in its effectiveness by any other authority.

Despite all the common features of national ideology, the difference between types of nationalism, which is decisive with regard to their integrative or disintegrative effect, ultimately lies in how the relationship between inside and outside that is initially constitutive for nationalism as such is concretely expressed. This is because 
the question of who may and who may not belong to a nation is answered in fundamentally different ways in the civic model of the nation, as Anthony D. Smith (1991) called it, compared to the ethnic conception of the nation.

Ideally, the civic nation justifies its conceptions of inclusion and exclusion through political commitment and a declared will to belong to the nation, and it binds these to the free self-determination of the individual, thus guaranteeing a homogeneous normative order as well as social heterogeneity. In the theory of the ethnic nation, on the other hand, the nation is based on an ethnic interpretation of the nation as a people. The concept of a people is not understood here in its pre-modern, situational meaning in the sense of masses or subjects, but in its existential, völkisch meaning as a 'people of culture and blood'. This ethnic nationalism strives for an identity and homogeneity between members of the ethnic group, the territory the group inhabits and its formal affiliation to the respective state organisation. It is, in other words, structurally disintegrative and directed against the factual reality of modern societies as socially heterogeneous places of continuous migration; it aims to compel social homogeneity and thus a homogeneous reality that never actually exists.

The moment of ethnicity is crucial here, especially as the constitutive foundation of the people understood as the most comprehensive possible ethnic collective. This view regards ethnic differentiation as a genuine feature of human existence. As a postulate, its theoretical core is the assumption that human social bonds have an inescapably ethnic basis. Ethnicity thus becomes a 'question of being', as Eugeen Roosens (1995: 35) puts it. In this respect, this position rejects the universalist postulate of equality and assumes that an essentialist ethnic difference and ethnic determination of human beings underlies all political and social action. The focus here is on an understanding of the 'ethnic community of fate' as a natural community, which rejects an orientation towards the individual as subject.

The creation of the subjective sense of belonging to the collective that is necessary for the concept of an ethnic nation structurally produces an image of the other alongside that of the collective itself, and this distinction theoretically anticipates a segregation carried out in reality. In constructing an ethnic history with myths, traditions, 
symbols, legends, special ways of dressing and cooking, rites, etc., ethno-national argumentation finds it necessary to exclude all those factors that might undermine a homogeneous image of the distinct (collective) self. In the very process of exclusion, the other becomes a potential threat to this distinct collective identity, because as soon as the rigid boundaries of self-reassurance soften, the separate identity that is created would also be endangered. Another sociologically decisive factor is that the ethnic collective is assigned a superior position over the individual; this position is linked to the demand for community homogeneity and thus for a social reality that it expects to be homogenised. The collective is considered to be a 'unique, "organic" community' (Kreutzberger 1993: 8) that must assert itself vis-à-vis its environment. Social conflicts of interest that objectively always exist within ethnic communities are edited out of the reality of people's lives, since ethnic primacy denies the actual relevance of these communities. To use Claus Gatterer's term: this ethno-nationalism is thus a 'total nationalism' (1972: 101 ), since ethnic identity is not seen as a question of private belief. Rather, through the dissolution of the space for possible political action, it is transformed from an individual offering of identity to a collective and normative compulsion to act.

\section{Homogeneous Normative Order and Social Heterogeneity}

State systems in the modern age are based on interests that must always stand in conflict with each other. Every system of conflict, however, also requires political unity as a homogeneous normative order, lest its existence be at risk. To cite Konrad Hesse's way of formulating this tension: establishing political unity does not mean 'producing a harmonious state of general agreement' (1999: 6). Hesse sees conflicts as the 'moving force' of a system that thereby protects society from immobility and paralysis. Nevertheless: the dilemma of modern rule is precisely that of equally guaranteeing both political unity and political conflict and, in this respect, not abandoning either the one or the other. From a constructivist perspective, then, conceptions of ethnicity can be justifiably labelled as socially created and invented, that is, as ultimately illegitimate. It remains a fact, however, that conceptions of ethnicity are given credence by a 
considerable number of people. They thus shape and often dominate social realities, perhaps precisely because they are irrational. The permanent tension between the homogeneous normative order and the heterogeneous reality of societies is objectively contested by ethnonational conceptions to the extent that these notions undermine social heterogeneity while, at the same time, remaining capable of exerting a subjectively integrative effect on the social level. This assumes, of course, that it is possible to consistently transfer these concepts, in the pre-political form in which they exist in reality, into the private sphere, and thus that it is possible to politically neutralise them.

If this succeeds, then it becomes possible to formulate the question of how to reorder a homogeneous normative order beyond the nation state - and this reordering would articulate minimal pre-conditions that could be used to establish a new, universalistic narrative as a normative model.

Samuel Salzborn is Adjunct Professor of Political Science at the Institute of Political Science at the University Giessen, Germany. His current research focusses on political theory, antisemitism and rightwing extremism. E-mail: samuel.salzborn@sowi.uni-giessen.de

\section{References}

Almond, G. A. and S. Verba. 1963. The Civic Culture: Political Attitudes and Democracy in Five Nations. Princeton, NJ: Princeton University Press.

Anderson, B. 1983. Imagined Communities: Reflections on the Origin and Spread of Nationalism. London: Verso.

Birsl, U. and S. Salzborn. 2014. 'Unwritten Constitutions of Political Rule:

Conceptual Approaches to Comparative Area Studies of Asia, the Middle East \& North Africa, and Europe'. ASIEN: The German Journal on Contemporary Asia 132: 12-25. http://asien.asienforschung.de/wp-content/ uploads/sites/6/2014/08/ASIEN_132_Birs1_Salzborn_Abstract.

Böckenförde, E.-W. 1976. Staat, Gesellschaft, Freiheit: Studien zur

Staatstheorie und zum Verfassungsrecht [State, society, freedom: Studies on the theory of state and constitutional law]. Frankfurt: Suhrkamp.

Elias, N. 1994. Studien über die Deutschen: Machtkämpfe und

Habitusentwicklung im 19. und 20. Jahrhundert [Studies on the Germans: Power struggles and habitual development in the 19th and 20th centuries], 2nd ed. Frankfurt: Suhrkamp. 
Fraenkel, E. 1941. The Dual State: A Contribution to the Theory of Dictatorship. New York: Oxford University Press.

Fukuyama, F. 2011. The Origins of Political Order: From Prehuman Times to the French Revolution. New York: Farrar, Straus and Giroux.

Fukuyama, F. 2014. Political Order and Political Decay: From the Industrial Revolution to the Globalization of Democracy. London: Profile Books.

Gatterer, C. 1972. Erbfeindschaft Italien-Österreich [Hereditary enmity between Italy and Austria]. Vienna: Europa.

Göhler, G. (ed.). 1997. Institution - Macht-Repräsentation: Wofür politische Institutionen stehen und wie sie wirken [Institution - Power - Representation: How political institutions are created and how they work]. Baden-Baden, Germany: Nomos.

Gosewinkel, D. 2016. Schutz und Freiheit? Staatsbürgerschaft in Europa im 20. und 21. Jahrhundert [Protection and freedom? Citizenship in Europe in the 20th and 21st centuries]. Berlin: Suhrkamp.

Heller, H. (1928) 1992. 'Politische Demokratie und soziale Homogenität' [Political democracy and social homogeneity]. In Gesammelte Schriften Vol. 2: Recht, Staat, Macht [Collected writings vol. 2: Law, state and force], ed. Christoph Müller. Tübingen: Mohr Siebeck, 421-433.

Hesse, K. 1999. Grundzüge des Verfassungsrechts der Bundesrepublik Deutschland [Basic features of constitutional law of the Federal Republic of Germany]. Heidelberg: C. F. Müller.

Hobbes, T. (1651) 2010. Leviathan or The Matter, Forme, and Power of a Commonwealth Ecclesiasticall and Civil. New Haven, CT: Yale University Press, 2010

Jellinek, G. (1900) 1914. Allgemeine Staatslehre [The general doctrine of the state], 3rd ed. Berlin: O. Häring.

Kant, I. (1797) 2018. The Metaphysics of Morals. Trans. M. Gregor. Ed. L. Denis. Cambridge: Cambridge University Press.

Koselleck, R. 1992. 'Volk, Nation, Nationalismus, Masse' [People, nation, nationalism, masses]. In O. Brunner, W. Conze and R. Koselleck (eds), Geschichtliche Grundbegriffe: Historisches Lexikon zur politisch-sozialen Sprache in Deutschland [Basic historical concepts: Historical lexicon on political-social language in Germany], vol. 7. Stuttgart: Klett-Cotta, 141-431.

Kreutzberger, W. 1993. 'Rechtsradikalismus: Daten und Deutungen' [Rightwing radicalism: Data and interpreations]. In W. Kreutzberger (ed.), Aus der Mitte der Gesellschaft: Rechtsradikalismus in der Bundesrepublik [From the middle of society: Right-wing radicalism in the Federal Republic]. Frankfurt: Materialis Verlag, 7-18.

Lauth H.-J. and U. Liebert (eds). 1999. Im Schatten demokratischer Legitimität: Informelle Institutionen und politische Partizipation im interkulturellen Demokratienvergleich [In the shadow of democratic legitimacy: Informal institutions and political participation in an intercultural comparison of democracies]. Opladen, Germany: Verlag für Sozialwissenschaften. 
Luhmann, N. 1998. 'Der Staat des politischen Systems: Geschichte und Stellung in der Weltgesellschaft' [The state of the political system: History and position in world society]. In U. Beck (ed.), Perspektiven der Weltgesellschaft [Perspectives on world society]. Frankfurt: Suhrkamp, 345-380.

Neumann, F. L. 1944. Behemoth: The Structure and Practice of National Socialism 1933-1944 (with new Appendix), 2nd ed. New York: Harper and Row.

Renan, E. 2018. What Is a Nation? and Other Political Writings. Trans. and Ed. M. F. N. Giglioli. New York: Columbia University Press.

Roosens, E. 1995. 'Ethnicity as a Creation: Some Theoretical Reflections'. In K. Benda-Beckmann and M. Verkuyten (eds), Nationalism, Ethnicity and Cultural Identity in Europe. Utrecht, Netherlands: European Research Centre on Migration and Ethnic Relations, 30-39.

Salzborn, S. 2015. 'No Sovereignty without Freedom: Machiavelli, Hobbes and the Global Order in the Twenty-first Century'. Theoria: A Journal of Social and Political Theory 61 (144): 19-39. doi:10.3167/th.2015.6214402.

Salzborn, S. 2017. Kampf der Ideen: Die Geschichte politischer Theorien im Kontext [Battle of ideas: The history of political theories in context], 2nd ed. Baden-Baden, Germany: Nomos.

Schmitt, C. (1922) 1985. Political Theology: Four Chapters on the Concept of Sovereignty. Chicago: University of Chicago Press.

Schmitt, C. (1928) 2007. Constitutional Theory. Durham, NC: Duke University Press.

Smith, A. D. 1991. National Identity. London: Penguin Books.

Weber, M. (1921) 1978. Economy and Society: An Outline of Interpretive Sociology. Oakland: University of California Press.

Wehler, H.-U. 2001. Nationalismus: Geschichte - Formen - Folgen

[Nationalism: History - forms - consequences]. Munich: C.H. Beck. 